\title{
Analysis of daily physical activity of male and female middle school students according to periods
}

\author{
Jong-Hun Jang, Gyu-Il Lee* \& Jae-Young Park \\ Kyungpook National University · Kyung Il University
}

\begin{abstract}
[Purpose] The purpose of this study is to measure the daily physical activity of male and female middle school students according to the period (VD: vaction day, SNPE: school day no PE, SPE: school day with PE) by using 3-axis accelerometer, and to compare the characteristics of adolescent physical activity according to gender and period. [Methods] The subjects were 130 middle school students (68 male, 62 female students). Data collection was performed using a 3-axis accelerometer(GT3X model, ActiGraph). Collected data were converted into time by intensity and rate using physical activity analysis program (Actilife v6.11.9) and analyzed by statistical program (SPSS 25.0). One-way ANOVA and independent sample t-test were used for statistical analysis. Tukey's HSD was used as a post analysis. The statistical significance level was .05. [Results] As a result, during each periods(VD, SNPE, and SPE), except for MVPA(moderate to vigorous physical activity) time on SPE, sedentary and MVPA time were significantly higher in female students, and low intensity and total physical activity time were significantly higher in male students. For male students, total physical activity time was higher in the order of SPE, SNPE, and VD, and for female students, physical activity time during the semester(SNPE and SPE) was significantly higher than VD. For male students, MVPA time was significantly high in order of SPE, SNPE, and VD, and for female students, it was high in order of SPE, SNPE, and VD but only significant difference occurred between SPE and VD. For both male and female students, sedentary time was high in the order of VD, SNPE, and SPE, but the sedentary time during vacation was significantly higher than during the semester. [Conclusions] When summarizing the results, first, it was confirmed that school and physical education classes as a physical activity space play a significant role in physical activity, especially MVPA, of male and female middle school students, second, the physical activity effect of physical education class was found to be more effective in male students. Based on the results of this study, it is necessary to conduct studies on various grades and to explore various factors affecting physical activity in a complex way.
\end{abstract}

Key words: adolescent, level of free life physical activity, moderate-to-vigorous physical activity, physical education class, 3-axis accelerometer

논문 투고일 : 2020. 05. 28.

논문 수정일 : 2020. 08. 03 .

게재 확정일 : 2020. 09. 15 .

* 교신저자 : 이규일(mauri94@knu.ac.kr).

* 이 논문은 장종훈(2019)의 석사학위 논문 "시기별 (방학 중과 학기 중)과 학기 중 체육수업 유무에 따른 남녀 중학생의 일일 신 체활동 비교 분석"을 학술논문 성격에 따라 재구성한 논문이다.
서론

청소년기는 아동에서 성인으로 성장하는 중간단계로, 이 시기 신체활동은 신체적, 심리적, 사회적, 생활양식 발 달에 기여한다(Bailey, 2006; Strong et al., 2005). 또 한, 청소년기는 건강 관련 행태(behavior pattern)가 결 
정되는 시기로, 이 시기 형성된 신체활동 습관은 평생 건 강의 기초가 된다(Kim, 2011; Telama et al., 2005). 그러나 신체활동의 가치를 아는 사람은 많지만, 그 효과 를 누리는 사람은 많지 않다(Berger, 1996). 국내 통계 조사(MCST, 2018)나 국가별 비교 연구(Tremblay et al., 2016)에 따르면, 우리나라 청소년들의 신체활동 환 경은 열악하다. 6 개 대륙 38 개국 청소년의 신체활동 수 준과 환경 지표를 분석한 Tremblay et al. (2016)에 따 르면, 우리나라 청소년의 신체활동 수준과 좌식행동 수준 의 등급은 각 각 $\mathrm{D}-$ 와 $\mathrm{F}$ 로 최하 수준에 머물러 있다. 실 제로, 국내 초, 중, 고등학교 학령기 청소년의 신체활동 수준은 동일 연령대의 서구 국가 청소년에 비해 낮은 수 준을 보이고 있다(Kang \& Lee, 2015a; 2015b; Lee \& Kang, 2015; Shin et al., 2016). 이러한 측면에서, 우 리나라 청소년의 신체활동 증진을 위한 다양한 방안이 모 색되어야 한다.

청소년 신체활동 실태 연구는 신체활동 문제의 경각심 을 높이고 신체활동 증진과 제약 요인을 밝혀 줌으로써, 건강당국의 정책과 프로그램 개발의 기초 자료를 제공하 는데 유용하다(Welk, 2002). 서구 국가들은 청소년 건 강문제를 미래 사회의 중대 사안으로 규정하며 성인뿐만 아니라 청소년 신체활동 특성에 대한 광범위하고 다각적 인 실태 조사를 통해 청소년의 건강 및 신체활동 관련 정 책을 수립하고 있다(CPPSE, 2013). 이에 비해, 우리나 라 건강당국은 청소년기 건강문제를 체력이나 비만 등에 한정하며 신체활동 자체의 증진에 관심을 기울지 않고 있 다. 그 결과, 실효성 있는 청소년 신체활동 정책이 제시되 지 않고 있다. 이러한 측면에서, 청소년 신체활동 실태를 광범위하게 분석할 수 있는 일상생활 신체활동 실태 분석 연구가 활발히 보고될 필요가 있다.

최근 보고된 국내 청소년의 일상생활 신체활동 관련 실태 분석 연구들을 살펴보면, 첫째, 성별(Kang \& Bae, 2001; Kang \& Lee, 2015a; 2015b; Lee \& Kang, 2015; Park, 2015), 체력 (Gwon \& Rhee, 2014; Kim et al., 2008), 체중 상태 및 비만 유무(Kim, 2008; Lee e t al., 2015; Yoon, 2001), 시기별 (Lee et al., 2015; Lee \& Kang, 2016; Shin et al., 2016), 생활영역 및 장소별 (Kim et al., 2005; Lee \& Kang, 2015), 학교급 별(Kang \& Lee, 2015c) 신체활동 수준과 특성을 밝히
고 있다. 둘째, 설문 조사(Cho \& Kang, 2009; Kim, 2012)나 질적 연구(Lee, 2014)를 통해 일상생활에서 직 면하는 다양한 신체활동 제약요인들이 밝혀지고 있다. 이 를 통해, 우리나라 청소년의 신체활동 수준이 열악하고, 시기와 영역의 차이를 밝히고, 신체활동 소외 청소년의 문제 등을 밝히고 있다. 그러나, 다음과 같은 한계 역시 안고 있다.

첫째, 객관적인 신체활동 실태 분석 연구가 부족하다. 국내 연구들은 한국형 신체활동 행태 조사지나 국제 신체 활동 설문지 등의 자가기입형 설문지나 보수계에 의존해 일상생활 신체활동을 측정해 왔다. 그러나, 자가 기입형 신체활동 설문 조사 도구는 참가자의 기억에 의존하기 때 문에 신체활동 참여 시간을 과대 측정하는 한계가 있다 (Macfarlane et al., 2007; Tudor-Locke et al., 2011). 또한, 보수계는 임의 조작과 강도별 신체활동을 측정하는 데 한계가 있다(Welk, 2002). 반면, 3차원 가속계는 신 체활동을 3 차원으로 분석해 신체활동 강도별 (비활동, 저 강도, 중강도, 고강도, 매우 고강도) 신체활동 정보를 제 공하는 객관적 신체활동 측정도구로써 측정의 편리성과 타당도 및 신뢰도 측면에서 다른 측정도구들에 비해 우수 성을 인정받고 있다(Lee, 2012; Tudor-Locke et al., 2011). 일부 연구들이 가속도계를 활용해 일상생활 신체 활동을 측정 및 분석하고 있으나(Gwon \& Rhee, 2014; Kim et al., 2008; Lee et al., 2015), 여전히 소수에 불 과하다. 이러한 측면에서, 가속도계를 활용한 보다 객관 적인 일상생활 신체활동이 측정될 필요가 있다.

둘째, 측정 시점이 학기 중으로 한정된다는 한계가 있 다. 선행연구 검토 결과, Lee \& Kang(2016)의 연구를 제외한 국내 연구들 대부분은 학기 중 신체활동 실태를 측정 및 분석해 왔다. 시기를 분석의 기준으로 삼은 연구 들 역시 주중과 주말의 신체활동 특성을 보고하고 있다 (Lee et al., 2015; Shin et al., 2016). 그러나, 학령기 청소년의 일상생활 양상은 학기 중과 방학 중에 따라 극 명한 차이를 보인다(Kim et al., 2005). 즉, 학기 중의 주중, 주말뿐만 아니라 방학 중 신체활동 특성이 분석될 필요가 있다는 것이다. 특히, 학기 중과 방학 중 신체활동 비교는 신체활동 공간으로써 학교의 역할과 기여에 관한 정보를 제공한다는 데 의의가 있다. 전통적으로 학교는 좌식행동 시간의 높은 비율로 비판받아 왔으나, 최근 학 
교를 중심으로 하는 신체활동 비중이 높아지고 상대적으 로 여가시간 중 좌식생활의 비중이 높아지면서, 신체활동 의 대안적인 공간으로 재평가되고 있다(Cheung, 2019). 한편, 가속도계를 활용해 학기 중과 방학 중을 분석한 Lee \& Kang(2016)은 모든 강도에서 학기 중 신체활동 이 긍정적으로 나타났음을 보고하고 있으나, 소수의 학생 을 측정 대상(총 56명, 남 32명, 여 24명)으로 삼고 있으 며, 학교체육 활동(체육수업, 방과후 체육활동 등)이나 여가영역의 신체활동(태권도 학원, 교외 스포츠클럽 활 동 등)을 통제하지 않아, 학기 중 나타난 긍정적 변화가 학교생활의 일반적 효과인지, 아니면 학교체육 활동의 효 과인지에 관한 결론을 도출하는 데 한계가 있다. 이에, 학 기 중과 방학 중 신체활동 특성에 관한 비교분석 연구가 요청된다.

셋째, 체육수업 유무에 따라 일일 신체활동량을 분석 한 국내 연구가 부족하다. 최근 국외의 청소년 신체활동 관련 분야에서는 시기에 따른 신체활동 분석(예, 주중 vS 주말, 학기 중 vs 방학 중)뿐만 아니라, 특정 활동의 일일 신체활동 기여 정도를 파악하는 연구들이 활발히 보고되 고 있다. 대표적인 연구로, 체육수업의 유무(Fairclough et al., 2002; Meyer et al., 2013), 쉬는 시간과 점심시 간의 길이 (Nettlefold et al., 2011), 방과후 체육활동 유 무(Mears \& Jago, 2016) 등에 따른 학기 중 신체활동 특성을 분석하는 연구들이 있다. 체육수업의 신체활동 기 여도에 관한 분석 결과는 건강증진에 대한 학교체육의 역 할을 실증적으로 규명할 뿐만 아니라, 향후 학교체육 정 책 방향을 결정하는 데 유의미한 기초 자료를 제공할 수 있을 것으로 판단된다. 이에, 학기 중 신체활동량은 체육 수업 유무에 따라 측정하고 분석될 필요가 있다.

한편, 연령과 성별은 신체활동에 영향을 미치는 중요 한 요인들이다. 먼저, 연령 특성을 살펴보면, 중학교 시기 는 좌식생활을 주도하는 학업 시간(Kim \& Kim, 2019) 과 인터넷 및 스마트폰 사용 시간(Cho, 2019)이 증가하 는 시기이다. 실제로 초등학교 시기와 비교할 때 중학교 시기의 좌식시간은 평균 $10 \sim 20$ 분 이상 증가하고 (Pearson et al., 2017), 신체활동 시간은 급격히 감소된 다(Telama, 2009). 즉, 중학교 시기는 신체활동 행동이 변화하는 주요 시점이라는 것이다. 또한, 이 시기는 향후 신체활동 습관 형성에 중요한 시기이며, 실제로 10 대 초
반 형성된 신체활동 습관이 성인기 신체활동 습관으로 전 이되는 강도는 중강도 수준으로 평가된다(Biddle et al., 2010). 다음으로, 성별(gender)은 신체활동의 영향요인 중 가장 보편적인 요인이다(CPPSE, 2013). 즉, 측정대 상의 다른 조건이 같다면, 성별에 따라 신체활동 차이 (남>여)가 발생한다는 것이다. 성별 분석을 시도한 국내 연구들에서도 이같은 차이가 확인되고 있다(Lee \& Kang, 2015). 이러한 측면에서, 중학교 시기 남녀 학생 의 신체활동 특성에 관한 연구가 요청된다. 따라서 본 연 구에서는 세 시기(방학 중, 체육수업이 있는 날, 체육수 업이 없는 날)의 남녀 중학생 일일 신체활동을 측정하고, 이를 시기와 성별에 따라 분석하고자 한다. 이를 통해, 우 리나라 중학교 학령기 청소년의 일상생활 신체활동 수준 과 시기와 성별에 따른 특성을 살펴보고자 한다.

\section{연구방법}

\section{1. 연구 대상}

본 연구에서는 학급 규모, 학교체육시설 현황, 지리적 위치를 고려하여 $\mathrm{D}$ 시 소재 중학교 2 개교를 연구학교로 선정하였다. 연구대상자들은 학기 중 체육수업 유무 및 방학 중 총 3 회에 걸쳐 하루 동안 가속도계를 착용해야 한다. 가속도계 착용이 일상생활의 큰 불편함을 초래하는 것은 아니지만, 일정 수준의 불편함을 감수해야 하기 때 문에 정확한 데이터를 추출하기 위해서는 연구대상자의 성실성이 필요하다. 또한, 교외 신체활동의 영향을 배제 하기 위해 연구대상자들은 학교 밖 신체활동 프로그램에 참여하지 않는 학생이어야 한다. 이에, 편의 표집 방식에 따라 연구대상자를 선정하였다. 구체적으로, 교외 신체 활동에 참여하지 않는 학생들 중 측정에 성실히 참여해 줄 수 있는 남녀 학생들을 연구학교 체육교사로부터 추천 받았다. 추천받은 학생들에게 연구의 의의와 절차에 대해 충분히 설명한 후, 학생과 학부모의 동의를 구하였다. 연 구에 동의한 남녀 학생 총 151 명 (남학생 89명, 여학생 67 명)을 연구대상으로 선정하였으며, 이 중 측정 오류와 기기 미착용으로 인한 데이터를 제외한 130명(남학생 68 명, 여학생 62 명)의 자료를 최종 분석에 활용하였다. 
다만, 남학생은 3학년 학생들로만 구성된 반면, 중도 탈 락으로 인하여 여학생의 경우 1 학년과 3학년 학생으로 구성되었다. 연구대상의 특성은 〈Table 1〉에 제시되어 있다.

\section{2. 자료 수집}

본 연구에서는 ActiGraph에서 개발한 3차원 가속도 계 (GT3X 모델)를 활용하였다. 가속도계 측정은 연구 대 상자별로 1)방학 중(Vacation day, VD), 2)학기 중 체 육수업 있는 날(School day with Physical Education, $\mathrm{SPE}), 3$ )학기 중 체육수업 없는 날(School day No Physical Education, SNPE) 총 3회 이루어졌다. 측정 일은 연구학교 체육교사와 협의하여 학교 시간표 및 학교 일정을 고려하여 임의로 선택되었다(Cheung, 2019; Meyer et al., 2013). 단, 측정일 선택에 있어, $\mathrm{SPE}$ 와 $\mathrm{SNPE}$ 측정은 연구대상이 학기 중 체육수업을 제외한 교 내 체육활동(스포츠수업, 방과 후 체육활동 등)이 없는 날 이루어졌으며, $\mathrm{SPE}$ 는 연구 대상자들이 동일한 체 육수 업 활동(배드민턴)에 참여한 날 측정되었다. $\mathrm{VD}$ 측정에 서는 일상과 다르지 않은 하계 여름 방학 중 하루 동안 이 루어졌다.

모든 측정은 24 시간 동안 이루어졌다. 일일 신체활동 은 구비된 기기의 수량에 따라 시기별 회당 약 30 명씩 총 5 회에 걸쳐 측정되었다. 사전에 입수한 연구대상자의 정 보(키, 몸무게, 성별)를 기기에 입력하여 측정일의 예약 된 시간에 기기가 작동하도록 설정하였으며, 기기의 오류 가 생기지 않도록 충전과 작동 여부를 미리 확인하였다. 측정 당일, 측정 시 유의사항(수면 시간과 목욕 시간 탈 착, 임의로 가속계를 흔드는 행동 금지 등)을 교육한 후 기기를 연구대상자의 허리에 채워주었고, 다음 날 같은 시간에 기기를 회수하였다. 회수된 기기를 신체활동 분석

Table 1. Characteristics of research participants $($ Mean $\pm S D)$

\begin{tabular}{ccc}
\hline \hline & male(n=89) & female(n=67) \\
\hline Age(year) & $16.0 \pm 0$ & $15.2 \pm 0.97$ \\
Heigh(cm) & $169.8 \pm 6.34$ & $157.5 \pm 5.77$ \\
Weigh(kg) & $67.0 \pm 12.65$ & $51.6 \pm 8.05$ \\
BM(kg/m2) & $23.2 \pm 4.10$ & $20.7 \pm 2.75$ \\
\hline \hline
\end{tabular}

프로그램과 연결하여 데이터를 추출 및 저장하였으며, 측 정 시마다 이상의 과정을 반복하였다.

\section{3. 자료 분석}

측정된 자료는 Actilife 사에서 제공하는 신체활동 분 석프로그램(Actilife v6.11.9)에 입력해 운동강도별 시 간(분)으로 변환하였고, 변환된 자료는 통계프로그램 (SPSS 25.0)에 입력하여 분석하였다. 시기와 성별에 대 한 상호작용은 나타나지 않아, 시기별 분석은 남녀를 구 분하여 일원분산분석(One-way $\mathrm{ANOVA}$ )을 실시 후 Tukey's HSD를 사용하여 사후 검정하였고, 남녀 학생 간의 차이는 독립표본 $\mathrm{t}$-검정을 실시하였다. 연구문제와 관련한 모든 통계적 유의수준은 .05로 설정하였다.

\section{연구결과}

\section{1. 시기에 따른 남녀 중학생의 신체활동}

시기(VD, $\mathrm{SNPE}, \mathrm{SPE})$ 에 따른 강도별 신체활동(좌식 시간, 저강도, MVPA, 총 신체활동) 시간의 남녀 차이 결 과는 〈Table 2〉와 같다.

1) 방학 중 (VD) 신체활동

방학 중 모든 신체활동 유형에서 남녀 학생 간의 유의 한 차이가 나타났다. 남녀 학생의 좌식시간은 $1237.48 \pm$ 86.42 분(남)과 $1266.08 \pm 69.92$ 분(여), 저강도 신체활동 시간은 $155.10 \pm 72.65$ 분(남)과 $104.86 \pm 64.84$ 분(여), MVPA 시간은 $47.40 \pm 26.96$ (남)분과 $69.00 \pm 50.77$ 분

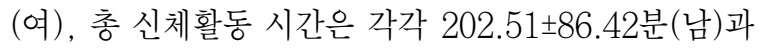
$173.86 \pm 69.98$ 분(여)으로 나타났으며, 좌식시간과 MVPA 시간은 여학생에게서, 저강도 시간과 총 신체활동 시간은 남학생에게서 유의하게 높게 나타났다.

\section{2) 체육수업 없는 날(SNPE) 신체활동}

체육수업이 없는 날에서도 모든 신체활동 유형에서 남 녀 학생간의 유의한 차이가 나타났다. 남녀 학생의 좌식 시간은 $\quad 1141.93 \pm 78.58$ 분(남)과 $1192.81 \pm 71.55$ 분 
Table 2. Comparison of levels of physical activity between male and female students according to measurement time and intensity.

\begin{tabular}{|c|c|c|c|c|c|c|}
\hline period & variance & gender & $\mathrm{N}$ & PA time(min.) & $t(\mathrm{df})$ & $p$ \\
\hline \multirow{8}{*}{ VD } & \multirow{2}{*}{ inactive - } & male & 68 & $1237.48 \pm 86.42$ & \multirow{2}{*}{$\begin{array}{c}-2.061 \\
(128)\end{array}$} & \multirow{2}{*}{$.041 *$} \\
\hline & & female & 62 & $1266.08 \pm 69.92$ & & \\
\hline & \multirow{2}{*}{ light } & male & 68 & $155.10 \pm 72.65$ & \multirow{2}{*}{$\begin{array}{l}4.145 \\
(128)\end{array}$} & \multirow{2}{*}{$.000^{*}$} \\
\hline & & female & 62 & $104.86 \pm 64.84$ & & \\
\hline & \multirow{2}{*}{ MVPA } & male & 68 & $47.40 \pm 26.96$ & \multirow{2}{*}{$\begin{array}{c}-3.066 \\
(128)\end{array}$} & \multirow{2}{*}{$.003^{* *}$} \\
\hline & & female & 62 & $69.00 \pm 50.77$ & & \\
\hline & \multirow{2}{*}{ total } & male & 68 & $202.51 \pm 86.42$ & \multirow{2}{*}{$\begin{array}{l}2.065 \\
(128)\end{array}$} & \multirow{2}{*}{$.041^{*}$} \\
\hline & & female & 62 & $173.86 \pm 69.98$ & & \\
\hline \multirow{8}{*}{ SNPE } & \multirow{2}{*}{ inactive - } & male & 68 & $1141.93 \pm 78.58$ & \multirow{2}{*}{$\begin{array}{c}-3.846 \\
(128)\end{array}$} & \multirow{2}{*}{$.000 * * *$} \\
\hline & & female & 62 & $1192.81 \pm 71.55$ & & \\
\hline & \multirow{2}{*}{ light } & male & 68 & $215.30 \pm 63.10$ & \multirow{2}{*}{$\begin{array}{l}5.837 \\
(128)\end{array}$} & \multirow{2}{*}{$.000^{* * *}$} \\
\hline & & female & 62 & $143.64 \pm 76.70$ & & \\
\hline & \multirow{2}{*}{ MVPA } & male & 68 & $60.74 \pm 28.48$ & \multirow{2}{*}{$\begin{array}{c}-3.498 \\
(128)\end{array}$} & \multirow{2}{*}{$.001^{* *}$} \\
\hline & & female & 62 & $90.91 \pm 64.56$ & & \\
\hline & \multirow{2}{*}{ total } & male & 68 & $276.04 \pm 78.45$ & \multirow{2}{*}{$\begin{array}{l}3.170 \\
(128)\end{array}$} & \multirow{2}{*}{$.002^{* *}$} \\
\hline & & female & 62 & $234.55 \pm 69.99$ & & \\
\hline \multirow{8}{*}{ SPE } & \multirow{2}{*}{ inactive- } & male & 68 & $1109.73 \pm 85.20$ & \multirow{2}{*}{$\begin{array}{c}-5.294 \\
(128)\end{array}$} & \multirow{2}{*}{$.000 * * *$} \\
\hline & & female & 62 & $1183.86 \pm 73.25$ & & \\
\hline & \multirow{2}{*}{ light } & male & 68 & $228.77 \pm 69.00$ & \multirow{2}{*}{$\begin{array}{l}6.296 \\
(128)\end{array}$} & \multirow{2}{*}{$.000^{* * *}$} \\
\hline & & female & 62 & $148.74 \pm 75.93$ & & \\
\hline & MVPA & male & 68 & $81.41 \pm 26.39$ & -1.870 & 064 \\
\hline & & female & 62 & $98.46 \pm 69.91$ & (128) & .004 \\
\hline & total & male & 68 & $310.18 \pm 83.33$ & 4.619 & $000 * * *$ \\
\hline & total & female & 62 & $247.20 \pm 70.90$ & (128) & $.000 \mathrm{rat}$ \\
\hline Mean- & $*<.05$ & $* *<.01$ & 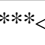 & & & \\
\hline
\end{tabular}

(여), 저강도 신체활동 시간은 $215.30 \pm 63.10$ 분(남)과 $143.64 \pm 76.70$ 분(여), MVPA 시간은 $60.74 \pm 28.48$ 분 (남)과 $90.91 \pm 64.56$ 분(여), 총 신체활동 시간은 $276.04 \pm 78.45$ 분(남)과 $234.55 \pm 69.99$ 분(여)로 나타났 으며, 방학 중 신체활동 양상과 유사하게 좌식시간과 MVPA 시간은 여학생에게서, 저강도 시간과 총 신체활 동은 남학생에게서 유의하게 높게 나타났다.

\section{3) 체육수업이 있는 날(SPE) 신체활동}

체육수업이 있는 날의 경우 MVPA 시간을 제외한 신 체활동 유형에서 남녀 학생간의 유의한 차이가 나타났다. 남녀 학생의 좌식시간은 $1109.73 \pm 85.20$ 분(남)과 $1183.86 \pm 73.25$ 분(여), 저강도 시간은 $228.77 \pm 69.00$ 분(남)과 $148.74 \pm 75.928$ 분(여), MVPA 시간은 각각 $81.41 \pm 26.39$ 분(남)과 $98.46 \pm 69.91$ 분(여), 총 신체활 동 시간은 $310.18 \pm 83.33$ 분(남)과 $247.20 \pm 70.90$ 분(여) 으로 나타났다. 좌식시간은 여학생에게서, 저강도 시간과 총 신체활동은 남학생에게서 유의하게 높게 나타났으며, MVPA 시간에서는 유의차가 나타나지는 않았으나, 다른 시기와 유사하게 여학생에게서 높은 경향이 나타났다.

\section{2. 성별에 따른 시기별 신체활동 시간 차이}

1) 남학생의 시기별 신체활동 비교

남학생의 총 신체활동 시간은 시기에 따라 유의한 차 이가 나타났으며 $(p=.000)$, 사후분석 결과, 체육수업 있 는 날(SPE), 체육수업 없는 날(SNPE), 방학 중(VD) 순 으로 높게 나타났다(Table 3).

Table 3. Comparison of total physical activity time of male students according to measurement time.

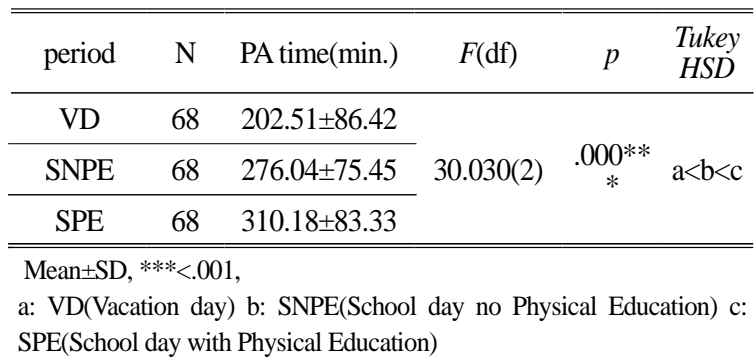

남학생의 강도별 신체활동의 시기에 따른 차이와 사후 분석 결과는 〈Table 4〉와 같다. 모든 강도에서 신체활동 시간의 시기별 차이는 유의하게 나타났으며, 사후분석 결 과, 좌식활동은 다른 두 시기(SNPE, SPE)에 비해 방학 중 $(\mathrm{VD})$ 에서 높게, 저강도 시간은 다른 두 시기(SNPE, $\mathrm{SPE})$ 에 비해 방학 중(VD)에서 낮게 나타났다. MVPA 시 간은 체육수업 있는 날(SPE), 체육수업 없는 날(SNPE), 방학 중(VD) 순으로 높게 나타났다(Figure 1). 
Table 4. Comparison of physical activity time male students according to intensity and measurement time.

\begin{tabular}{|c|c|c|c|c|c|c|}
\hline level & period & $\mathrm{N}$ & PA time(min.) & $F(\mathrm{df})$ & $p$ & $\begin{array}{l}\text { Tukey } \\
\text { HSD }\end{array}$ \\
\hline \multirow{3}{*}{ inactive } & VD & 68 & $1237.48 \pm 86.42$ & \multirow{3}{*}{$\begin{array}{c}43.077 \\
(2)\end{array}$} & \multirow{3}{*}{$.000^{* * *}$} & \multirow{3}{*}{$a>b, c$} \\
\hline & SNPE & 68 & $1141.93 \pm 78.58$ & & & \\
\hline & SPE & 68 & $1109.73 \pm 85.20$ & & & \\
\hline \multirow{3}{*}{ light } & $\mathrm{VD}$ & 68 & $155.10 \pm 72.65$ & \multirow{3}{*}{$\begin{array}{c}22.386 \\
(2)\end{array}$} & \multirow{3}{*}{$.000^{* * *}$} & \multirow{3}{*}{$a<b, c$} \\
\hline & SNPE & 68 & $215.30 \pm 63.10$ & & & \\
\hline & SPE & 68 & $228.77 \pm 69.00$ & & & \\
\hline \multirow{3}{*}{ MVPA } & VD & 68 & $47.40 \pm 26.96$ & \multirow{3}{*}{$\begin{array}{c}26.796 \\
(2)\end{array}$} & \multirow{3}{*}{$.000^{* * *}$} & \multirow{3}{*}{$\mathrm{a}<\mathrm{b}<\mathrm{c}$} \\
\hline & SNPE & 68 & $60.74 \pm 28.48$ & & & \\
\hline & SPE & 68 & $81.41 \pm 26.39$ & & & \\
\hline
\end{tabular}

Mean \pm SD, ${ }^{* * *<.001}$

a: VD(Vacation day) b: SNPE(School day no Physical Education)

c: SPE(School day with Physical Education)

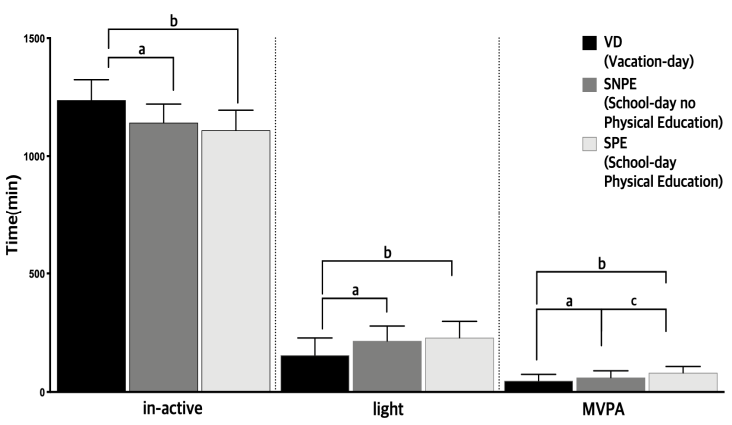

Fig. 1. Multi comparison of physical activity time of male students according to intensity and three measurement period.

* Significant differences $(\mathrm{p}<0.05)$ indicated, a; between VD and SNPE, b; between VD and SPE, c; between SNPE and SPE.

2) 여학생의 시기별 신체활동 비교

여학생의 총 신체활동 시간은 시기에 따라 유의한 차 이가 나타났으며, 사후분석 결과, 방학 중 $(\mathrm{VD})$ 총 신체 활동 시간이 다른 두 시기(SNPE, SPE)에 비해 낮게 나 타났다(Table 5).

여학생의 강도별 신체활동의 시기에 따른 차이와 사후 분석 결과는 〈Table 6 >과 같다. 모든 강도에서 신체활동 시간의 시기별 차이는 유의하게 나타났으며, 사후분석 결 과, 좌식활동은 다른 두 시기 (SNPE, SPE) 에 비해 방학 중 $(\mathrm{VD})$ 에서 높게, 저강도 시간은 다른두 시기 $\mathrm{SNPE}$, $\mathrm{SPE})$ 에 비해 방학 중(VD)에서 낮게 나타나 남학생 결과 와 유사한 경향을 보였다.
Table 5. Comparison of total physical activity time of female students according to measurement time.

\begin{tabular}{|c|c|c|c|c|c|}
\hline period & $\mathrm{N}$ & PA time(min.) & $F(\mathrm{df})$ & $p$ & $\begin{array}{l}\text { Tukey } \\
\text { HSD }\end{array}$ \\
\hline VD & 62 & $173.86 \pm 69.98$ & \multirow{3}{*}{$\begin{array}{c}19.288 \\
(2)\end{array}$} & \multirow{3}{*}{$.000 *$} & \multirow{3}{*}{$a<b, c$} \\
\hline SNPE & 62 & $234.55 \pm 69.99$ & & & \\
\hline SPE & 62 & $247.20 \pm 70.90$ & & & \\
\hline
\end{tabular}

a: VD(Vacation day) b: SNPE(School day no Physical Education)

c: SPE(School day with Physical Education)

Table 6. Comparison of physical activity time female students according to intensity and measurement time

\begin{tabular}{|c|c|c|c|c|c|c|}
\hline level & time & $\mathrm{N}$ & PA time(min.) & $F(\mathrm{df})$ & $p$ & $\begin{array}{l}\text { Tukey } \\
\text { HSD }\end{array}$ \\
\hline \multirow{3}{*}{ inactive } & VD & 62 & $1266.08 \pm 69.92$ & \multirow{3}{*}{$\begin{array}{c}24.619 \\
-\quad(2)\end{array}$} & \multirow{3}{*}{$\begin{array}{c}.000^{* *} \\
*\end{array}$} & \multirow{3}{*}{$a>b, c$} \\
\hline & SNPE & 62 & $1192.81 \pm 71.55$ & & & \\
\hline & SPE & 62 & $1183.86 \pm 73.25$ & & & \\
\hline \multirow{3}{*}{ light } & VD & 62 & $104.86 \pm 64.84$ & \multirow{3}{*}{$\begin{array}{c}6.758 \\
(2)\end{array}$} & \multirow{3}{*}{$.001^{*}$} & \multirow{3}{*}{$\mathrm{a}<\mathrm{b}, \mathrm{c}$} \\
\hline & SNPE & 62 & $143.64 \pm 76.70$ & & & \\
\hline & SPE & 62 & $148.74 \pm 75.93$ & & & \\
\hline \multirow{3}{*}{ MVPA } & VD & 62 & $69.00 \pm 50.77$ & \multirow{3}{*}{$\begin{array}{c}3.744 \\
(2)\end{array}$} & \multirow{3}{*}{$.025^{*}$} & \multirow{3}{*}{$\mathrm{a}<\mathrm{c}$} \\
\hline & SNPE & 62 & $90.91 \pm 64.56$ & & & \\
\hline & SPE & 62 & $98.45 \pm 69.91$ & & & \\
\hline
\end{tabular}

MVPA 시간은 남학생 결과와 다르게 체육수업 있는 날 (SPE)에서만 방학 중(VD)보다 높게 나타났다(Figure 2).

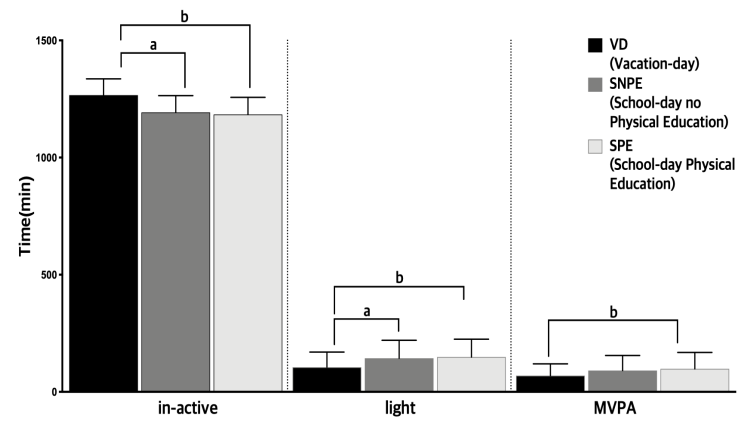

Fig. 2. Multi comparison of physical activity time of male students according to intensity and three measurement period.

* Significant differences $(\mathrm{p}<0.05)$ indicated, a; between VD and SNPE, b; between VD and SPE, c; between SNPE and SPE. 


\section{논의}

본 연구에서는 3 차원 가속도를 활용해, 학교 등교와 체육수업 유무에 따라 세 시기(VD, SNPE, SPE)의 강도 별 (비활동, 저강도, 중강도 이상) 일일 신체활동 시간을 측정하였다. 연구 결과, 남녀 학생의 신체활동량은 $\mathrm{SPE}$, $\mathrm{SNPE}, \mathrm{VD}$ 순으로 나타났으며, 연구의 주요 결과를 중심 으로 중학교 학령기 청소년의 일상생활 신체활동 특성을 살펴보면 다음과 같다.

첫째, W.H.O.(2019)의 청소년기 일일 신체활동 권장 기준(일일 MVPA 60분 이상)의 충족률은 학교 등교 유 무에 따라 학기 중 전체 $57.31 \%$ (남 $60.29 \%$, 여 $54.03 \%$ )와 VD 36.15\%(남 26.47\%, 여 46.77\%)로 나 타났다. 또한 학기 중 체육수업 유무에 따른 충족률은 $\mathrm{SNPE} 50 \%$ (남 $42.64 \%$, 여 58.06\%)와 SPE $64.61 \%$ (남 $77.94 \%$, 여 50\%)로 나타났다. 유사한 연령대(만 10 14세)의 학기 중 일일 신체활동 충족률을 보고한 국 외 연구들은 충족 수준을 $77.3 \%$ 94\%(남)와 50 79\%(여)로 밝히고 있다(Guerra et al., 2003; Riddoch et al., 2004; Santos et al., 2003). 측정 대상 의 연령, 인종, 민족, 비만 및 체중 상태, 기타 인구통계학 적 변인 등에 따른 차이와 신체활동 강도 설정 기준 (cut-point) 설정 및 측정 기간 등의 문제로 연구결과의 직접적인 비교에 한계가 있지만, 이 연구의 결과는 우리 나라 중학교 학령기 청소년의 신체활동 수준이 상대적으 로 저조하다는 것을 알려준다. 가장 활발한 $\mathrm{SPE}$ 에서도 전체 남녀 중학생의 약 $35 \%$ 가 신체활동 충족 기준을 달 성하지 못하며, 학교에 등교하지 않는 방학 동안에는 불 과 $36 \%$ 만이 신체적으로 건강하게 살아가고 있다. 이러 한 측면에서, 국내 청소년들의 MVPA 증진에 관심을 기 울일 필요가 있다.

둘째, MVPA 측면에서 시기별 $(\mathrm{VD}, \mathrm{SNPE}, \mathrm{SPE})$ 특 성을 살펴보면, 먼저, 학교 등교 유무에 따라, $\mathrm{SNPE}$ 의 MVPA 시간은 VD에 비해 높게 나타났다(남학생 +13.34 분, 여학생 +21.91 분). 가속도계를 활용해 방학 중과 학기 중 일상생활 신체활동을 비교한 Lee \& $\operatorname{Kang}(2016)$ 은 남녀 학생의 MVPA 차이를 각각 $+8.6 \%$ 와 $+6.7 \%$ 로 보고하며 이 연구의 결과를 지지한다. 또 한, 국제 신체활동 설문지를 통해 학교영역과 여가영역의
신체활동을 비교한 Lee \& Kang(2015) 역시 학교에서 의 MVPA 시간이 여가에서보다 약 1.6 배 이상 높다고 밝 히고 있다. 이런 점에서, 학교는 청소년의 활발한 신체활 동이 일어나는 공간이다.

그 이유를 살펴보면, 학교 자체는 좌식활동 시간이 높 지만, 다양한 신체활동 참여 기회를 제공하기 때문이다. 시간대별 MVPA를 측정한 Nettlefold et al. (2011)에 따르면, 학교에서 학생들은 체육수업을 포함한 정규 수업 시간(남: 39.9 분, 여: 33.8 분), 쉬는 시간(남: 5.3 분, 여: 3.8 분), 점심시간(남: 15.6 분, 여: 12.5 분)에 중고강 도 이상의 신체활동에 참여한다. 학생들은 학교생활을 하 면서 자연스럽게 약 50 분(여) 60 분(남) 정도의 MVPA 에 참여할 수 있다. 특히, 일부 연구들은 점심시간의 $\mathrm{MVPA}$ 시간이 체육수업보다 더 높다는 결과를 제공할 정 도로 학생들에게 신체적으로 적극적인 활동을 제공하는 시간이다(Song et al., 2010). 학교 내 뿐만 아니라, 학 교생활은 등하교 교통활동을 통해 하루 $\mathrm{MVPA}$ 의 약 $5 \sim 10 \%$ 를 제공한다(CPPSE, 2013). 학교 내 신체활동 이 활발한 이유를 밝힌 질적연구들은 신체활동 시설(체 육관, 운동장, 복도 등)의 접근성, 풍부한 사회 관계적 자 원(동료 학생들), 교육과정 체계 등을 그 이유로 밝히고 있다(Weiss, 2000). 이렇게 볼 때, 학교는 잠재적 신체 활동 환경이며, 청소년 신체활동의 전진 기지로서 학교의 역할과 과제에 대해 보다 진지한 정책적 및 교육적 논의 가 제기될 필요가 있다.

다음으로, 체육수업 유무에 따라, SPE의 MVPA 시간 은 $\mathrm{SNPE}$ 에 비해 남녀 학생 각각 +20.67 분과 +7.55 분 높았고, $\mathrm{SPE}$ 와 $\mathrm{VD}$ 의 시간 차이(남: +34.01 분, 여: +29.46)는 더 현저하게 나타났다(Figure 3). 일일 MVPA 시간에 대한 체육수업의 기여도를 밝힌 연구들은 체육수업 MVPA가 기대만큼 높지 않더라도 일일 평균 $\mathrm{MVPA}$ 의 34\%(남)와 26\%(여)를 제공한다고 밝히고 있 다(Gråstén et al., 2015). 기여 수준을 낮게 평가한 연 구들에서도 그 기여도는 $16.5 \%$ (Cheung, 2019)와 $11 \%$ (Wickel \& Eisenmann, 2007)로 보고되고 있다. Morgan et al.(2007)에 따르면, 일일 신체활동의 약 30 분 이상을 책임지는 체육수업은 학령기 청소년들이 하루 중 신체적으로 가장 활발한 시간이다. 이렇게 볼 때, 체육 수업은 학령기 청소년들의 $\mathrm{MVPA}$ 증진에 가장 중요한 시 
간임에 분명하다.

특히, 체육수업은 벌충 이론으로 설명되지 않는다는 점에서 그 가치가 독보적이다. 벌충 이론이란 한 영역에 서 신체활동 시간이나 에너지 소비량이 증가되면 다른 영 역에서 감소되어 전체적으로 안정적인 수준을 유지한다 는 주장이다(Rowland, 1998). 이를테면, 학교에서의 MVPA 시간이 증가하면 그 만큼 여가영역 MVPA 시간의 감소로 이어지게 된다는 것이다(Slingerland et al., 2012). 그러나, 체육수업과 여가영역 신체활동의 관련성 을 분석한 연구들은 체육수업으로 인해 증가된 MVPA가 여가영역 $\mathrm{MVPA}$ 의 감소로 벌충되지 않는다(Gidlow et al., 2008; Meyer et al., 2013). 이 연구 역시 SPE의 MVPA 시간은 하루 MVPA의 (+)요인임을 밝히며, 체육 수업은 벌충이론으로 설명되지 않는다는 점을 지지한다. 즉, 체육수업의 MVPA는 다른 영역들과 경쟁하지 않는 플러스 알파 효과를 갖는다는 것이다. 이러한 측면에서, 체육수업을 통해 MVPA를 증진하기 위한 노력이 요청된다.

셋째, 성별 신체활동 특성을 살펴보면, 모든 시기에서 총 신체활동은 남학생이 높았던 것과 달리, MVPA 시간 은 여학생에게서 높게 나타났다(Figure 3). 청소년 신체 활동 특성을 종합적으로 보고한 $\operatorname{CPPSE}(2013)$ 에 따르 면, 좌식활동 시간은 여학생이 높고, 저강도 활동은 혼합 된 결과가 나타나지만, 총 신체활동 시간과 MVPA 시간 은 모두 남학생이 높다. 국내 연구들 역시 이러한 국외 연 구 결과와 유사한 결과를 보고한다(Kang \& Lee, $2015 \mathrm{a} ; 2015 \mathrm{~b})$. 그러나, 일상생활 신체활동 결과를 메 타분석한 Ekelund et al. (2012)에서는 상이한 연령대 (예, 10 15세, 9 16세 등)를 포함하고 있는 가속도계 연구들은 연령대가 낮은 집단의 경우 기존의 성별 결과와 반대의 MVPA 결과(여남)들이 다수 보고되어 있다. 즉, 동일 연령이라면 성별이 MVPA의 보다 강력한 변인이지 만, 연령이 다를 경우 성별 차이 효과는 연령에 의해 상쇄 되거나 역전될 수 있다는 것이다. 이 연구의 학년 특성은 〈Table 7)과 같다. 같은 학년의 남녀 학생 간 MVPA는 남학생이 높은 반면, 중1 여학생의 MVPA는 중3 남학생 에 비해 월등하게 높게 나타나고 있다. 이렇게 볼 때, 이 연구에서의 상반된 성별 차이 결과는 낮은 연령이라는 정 적 요인이 여성이라는 부적 요인에 비해 더 크게 작용한 결과로 추론된다.

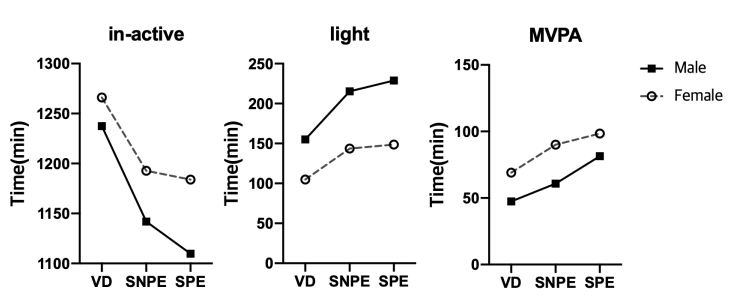

Figure 3. Multi comparison of physical activity time according to gender and three measurement period.

Table 7. Average MVPA of male and female students according to grade levels.

\begin{tabular}{|c|c|c|c|c|}
\hline time & gender & grade & $\mathrm{N}$ & PA time(min) \\
\hline \multirow{3}{*}{ VD } & male & 9th & 68 & $47 \pm 26.96$ \\
\hline & female & 9th & 37 & $37 \pm 16.94$ \\
\hline & female & 7th & 25 & $115 \pm 47.84$ \\
\hline \multirow{3}{*}{ SNPE } & male & 9th & 68 & $60 \pm 28.48$ \\
\hline & female & 9th & 37 & $48 \pm 24.07$ \\
\hline & female & 7th & 25 & $154 \pm 52.04$ \\
\hline \multirow{3}{*}{ SPE } & male & 9th & 68 & $81 \pm 26.39$ \\
\hline & female & 9th & 37 & $49 \pm 19.93$ \\
\hline & female & 7th & 25 & $170 \pm 53.25$ \\
\hline
\end{tabular}

시기별 성별 차이를 살펴보면, $\mathrm{VD}$ 와 비교한 $\mathrm{MVPA}$ 시 간의 증가폭은 $\mathrm{SNPE}$ 와 $\mathrm{SPE}$ 모두에서 남학생이 여학생 보다 크게 나타나고 있다. 뿐만 아니라, SNPE와 비교한 남학생의 SPE MVPA 증가는 여학생의 2 배 가까이 높은 것으로 확인된다. 이러한 차이는 앞서 살펴본 청소년 일 일 신체활동 권장 기준 충족률에서도 나타난다. $\mathrm{VD}$ 와 $\mathrm{SNPE}$ 에서의 충족률은 여학생이 높지만, $\mathrm{SPE}$ 의 충족률 은 남학생에게서 월등히 높게 나타나고 있다. 이러한 결 과는 등교와 체육수업 유무에 따른 신체활동 효과가 남학 생에게 집중되고 있다는 것이며, 다른 측면에서, 여학생 의 학교와 체육수업의 신체활동 조건이 상대적으로 열악 하다는 것을 시사해 준다. 이러한 측면에서, 여학생이 보 다 학교와 체육수업의 효과를 누릴 수 있는 방안이 모색 될 필요가 있다. 


\section{결론 및 제언}

본 연구를 통해 다음과 같은 결론을 얻을 수 있었다. 첫 째, 시기에 따른 남녀 중학생의 총 신체활동과 MVPA 시 간은 학기 중 체육수업 있는 날, 학기 중 체육수업 없는 날, 방학 중 순으로 나타났다. 즉, 학교영역과 체육수업이 남녀 중학생의 신체활동에 유의미한 역할을 한다는 것이 다. 둘째, 체육수업이 있는 날의 총 신체활동과 MVPA 시 간의 증가율은 남학생에게서 더 높게 나타났다. 이는 체 육수업에 대한 효과의 성별차이가 존재하는 증거이며, 그 수혜를 남학생이 더 누리고 있다는 결과이다. 다만, 본 연 구에 참여한 여학생들의 경우, 나이가 다른 학생들의 자 료가 합쳐진 결과이므로 추후 연구에서는 동일한 나이로 제한하여 보다 면밀한 분석을 실시하는 것이 필요하다. 한편, 실험에 참가한 학생들 중 일일 신체활동 권장 기준 (MVPA 60분 이상)을 달성한 학생의 비율은 체육수업이 있는 날 $(64.61 \%)$, 체육수업이 없는 날 $(50 \%)$, 방학 중 (36.15\%)에 머물고 있다. 이러한 실태 분석 결과를 토대 로, 청소년 신체활동 문제에 대한 건강당국과 교육당국의 지속적인 관심, 특히 여가영역의 좌식화 문제를 해결하 고, 포괄적 관점에서 학교영역의 신체활동을 증진시킬 수 있는 방안에 대한 정책적 노력이 요청된다.

마지막으로, 본 연구를 바탕으로 후속연구를 제안하 면, 첫째, 본 연구와 동일한 방식으로 다른 학교급(초등 학교, 고등학교, 대학교)과 학년에 대한 시기별 실태 분 석이 필요하다. 이를 통해, 각 연령대 혹은 학교급별 학교 영역과 체육활동 역할 및 여가영역의 상대적 문제 등에 대한 다각적으로 분석이 이루어질 필요가 있다. 둘째, 신 체활동 측정과 함께 신체활동에 영향을 미치는 요인들 (예, 신체적 요인, 심리적 요인, 사회적 요인, 문화적 요 인, 사회경제학적 요인 등)에 대한 연구가 추가될 필요가 있다. 셋째, 실태 분석 결과를 토대로 건강당국의 청소년 건강 정책을 견인할 수 있는 정책 연구, 교육당국의 실제 적인 교육적 투입 전략을 모색하기 위한 신체활동 증진 프로그램 연구들이 병행될 필요가 있다. 마지막으로, 객 관적인 신체활동 측정 도구를 활용해 청소년 신체활동을 이해할 수 있는 자료들이 지속적으로 확보되어야 한다.

\section{참고문헌}

Bailey, R. (2006). Physical education and sport in schools: A review of benefits and outcomes. Journal of school health, 76(8), 397-401.

Berger, B. G. (1996). Psychological benefits of an active lifestyle: What we know and what we need to know. Quest, 48(3), 330-353.

Biddle, S. J., Pearson, N., Ross, G. M., \& Braithwaite, R. (2010). Tracking of sedentary behaviours of young people: a systematic review. Preventive medicine, 51(5), 345-351.

Cheung, P. (2019). School-based physical activity opportunities in PE lessons and after-school hours: Are they associated with children's daily physical activity?. European Physical Education Review, 25(1), 65-75.

Cho, H. (2019). A study on the solution for the internet, smartphone, and internet game addiction of teenagers. Korean Journal of Youth Studies, 26(10), 291-310.

Cho, J. \& Kang, B. (2009). Determinants of physical activity in environmental and social factor : A review. The Korean Journal of Measurement and Evaluation in Physical Education and Sports Science, 11(3), 87-104.

CPPSE(Committe on Physical Activity and Physical Education in the School Environment) (2013). Educating the Student body: Taking Physical Activity and Physical Education to School. Washington, D.C: THE NATIONAL ACADEMIES PRESS.

Ekelund, U., Luan, J. A., Sherar, L. B., Esliger, D. W., Griew, P., Cooper, A., \& International Children's Accelerometry Database (ICAD) Collaborators. (2012). Moderate to vigorous physical activity and sedentary time and cardiometabolic risk factors in children and adolescents. Jama, 307(7), 704-712.

Fairclough, S., Stratton, G., \& Baldwin, G. (2002). The contribution of secondary school physical education to lifetime physical activity. European physical education review, 8(1), 69-84.

Gidlow, C. J., Cochrane, T., Davey, R., \& Smith, H. (2008). In-school and out-of-school physical activity in primary and secondary school children. Journal of sports sciences, 26(13), 1411-1419.

Gråstén, A., Watt, A., Hagger, M., Jaakkola, T. \& Liukkonen, J. (2015). Secondary school students' physical activity participation in physical education classes - The expectancy-value theory approach. The Physical Educator 
72(2), 340-358.

Guerra, S., Santos, P., Ribeiro, J. C., Duarte, J. A., Mota, J., \& Sallis, J. F. (2003). Assessment of Childrenís and Adolescentsí Physical Activity Levels. European Physical Education Review, 9(1), 75-85.

Gwon, O. S. \& Rhee, E. (2014). The relation of physical activity volume by Lifecorder and fitness in primary school student -comparison with Japanese students-. The Journal of Child Education, 23(2), 25-37.

Kang, H. \& Lee, G. (2015a). Physically Active Lifestyle of Korean Elementary School Students in Fifth and Sixth Grade and an Analysis of Gender Difference. The Korean Journal of Elementary Physical Education, 21(1), 125-136.

Kang, H. \& Lee, G. (2015c). Comparison of Levels and Areas of Physically Active Lifestyle among Female Students in Korean Elementary, Middle, and High Schools. The Korean Journal of Physical Education, 54(6), 197-208.

Kang, H. K. \& Lee, G. I. (2015b). Levels and areas of physically active lifestyle among Korean middle school students and relationships to physical self-efficacy. Korean Journal of Sport Science, 26(4), 904-916.

Kang, J. S. \& Bae, M. Y. (2001). A Study on the Daily Physical Activity in Elementary School Students. Korean Journal of Sport Pedagogy, 8(1), 59-72.

Kim, H. J., Kang, S. J., \& Park, J. H. (2005). Patterns of Energy Expenditure by Site- and Day-specific Physical Activity. The Korean Journal of Measurement and Evaluation in Physical Education and Sports Science, 7(1), 89-102.

Kim, J. S. (2012). Adolescent Physical Activity and Community Factors. Journal of Korean Society of Child Welfare. 37, 165-185.

Kim, S., \& Kim, J. (2019). Korea child and youth panel survey X: Data analysis report - youth lifetime type. National Youth Policy Institute Research Report. Sejong: National Youth Policy Institute.

Kim, W. K. (2011). The Relationship among Life Habits, Subjective Health Status, Physical Fitness of Middle School Students. Journal of Sport and Leisure Studies, 43(2), 1023-1032.

Kim, Y. H. (2008). Adolescents` Physical Activity and Its Related Perceived Benefits and Barriers According to Body Fat. Korean Society of Sport Psychology, 19(4), 73-86.

Kim, Y. S., Kong, S. A., Lee, O., Kim, J. W., Kim, S. S., \& Park, I.,
H. (2008). The relation between physical activity and fitness in children. Exercise science, 17(4), 495-504.

Lee, G. \& Kang, H. (2016). Analysis of Levels of Physical Activity between Semester and Vacation among Middle School Students: Using Three Dimensional Accelerometer. The Korean Journal of Physical Education, 55(4), 253-261.

Lee, G. (2014). Exploring on physically active lifestyle pattern and constrains of high school girl in city. Korean Journal of Sport Science, 25(4), 860-879.

Lee, G., \& Kang, H. (2015). An Analysis of Gender Difference on Physically Active Lifestyle among Korean Middle School Students. Korean Journal of Sport Pedagogy, 22(1), 53-70.

Lee, M. Y. (2012). Criterion and Convergent Validity Evidences of an Accelerometer and a Pedometer. Korean Journal of Measurement and Evaluation in Physical Education and Sports Science, 14(2), 1-13.

Lee, Y. S., Jeon, H. J., \& Kim, H. J. (2015). Assessment of Physical Activity on weekdays and weekend for Obesity Children in Elementary School. The Korean Journal of Elementary Physical Education, 21(3), 75-83.

Macfarlane, D.J., Lee, C.C.Y., Ho, E.Y.K., \& Chan, D.T.S. (2007). Reliability and validity of the Chinese version of IPAQ (short, last 7 days). Journal of Science and Medicine in Sport, 10(1), 45-51.

MCST(Ministry of Culture, Sports and Tourism) (2018). 2018 National Life sports Participation Survey. Sejong: Ministry of Culture, Sports and Tourism.

Mears, R., \& Jago, R. (2016). Effectiveness of after-school interventions at increasing moderate-to-vigorous physical activity levels in 5-to 18-year olds: a systematic review and meta-analysis. British Journal of Sports Medicine, 50(21), 1315-1324

Meyer, U., Roth, R., Zahner, L., Gerber, M., Puder, J. J., Hebestreit, H., \& Kriemler, S. (2013). Contribution of physical education to overall physical activity. Scandinavian journal of medicine \& science in sports, 23(5), 600-606.

Nettlefold, L., McKay, H. A., Warburton, D. E. R., McGuire, K. A., Bredin, S. S. D., \& Naylor, P. J. (2011). The challenge of low physical activity during the school day: at recess, lunch and in physical education. British journal of sports medicine, 45(10), 813-819.

Park, H. R. (2015). An Experiential Study of daily life experiences and affect states depending on levels of physical activity. The 
Korean Journal of Elementary Physical Education, 21(1), 93-108.

Pearson, N., Haycraft, E., Johnston, J. P., \& Atkin, A. J. (2017). Sedentary behaviour across the primary-secondary school transition: A systematic review. Preventive medicine, 94, 40-47.

Riddoch, C. J., Andersen, L. B., Wedderkopp, N., Harro, M., Klasson-Heggebø, L., Sardinha, L. B., ... \& Ekelund, U. L. F. (2004). Physical activity levels and patterns of 9-and 15-yr-old European children. Medicine \& Science in Sports \& Exercise, 36(1), 86-92.

Rowland, T. W. (1998). The biological basis of physical activity. Medicine \& Science in Sports \& Exercise 30(3): 392 - 399.

Santos, P., Guerra, S., Ribeiro, J. C., Duarte, J. A., \& Mota, J. (2003). Age and gender-related physical activity. Journal of Sports Medicine and Physical Fitness, 43(1), 85-89.

Shin, H. M., Jeon, J. H., \& Kim, E. K. (2016). Assessment of Pedometer Counts, Physical Activity Level, Energy Expenditure, and Energy Balance of Weekdays and Weekend in Male High School Students. Journal of THE KOREAN DIETETIC ASSOCIATION, 22(2), 131-142.

Slingerland, M, Borghouts, LB, Hesselink, MKC (2012). Physical activity energy expenditure in Dutch adolescents: Contribution of active transport to school, physical education, and leisure time activities. The Journal of School Health 82(5): 225 - 232.

Song, K., Park, H., Lee, H., \& Lee, T. (2010). Physical Activity Levels of 7th Graders in PE Class and Lunch Period. The Korean Journal of Measurement and Evaluation in Physical Education and Sports Science, 12(2), 53-64.

Strong, W. B., Malina, R. M., Blimkie, C. J., Daniels, S. R., Dishman, R. K., Gutin, B., ... \& Rowland, T. (2005). Evidence based physical activity for school-age youth. The Journal of pediatrics, $146(6)$, 732-737.

Telama, R. (2009). Tracking of physical activity from childhood to adulthood: a review. Obesity facts, 2(3), 187-195.

Telama, R., Yang, X., Viikari, J., Välimäki, I., Wanne, O., \& Raitakari, O. (2005). Physical activity from childhood to adulthood: a 21-year tracking study. American journal of preventive medicine, 28(3), 267-273.

Tremblay, M. S., Barnes, J. D., González, S. A., Katzmarzyk, P. T., Onywera, V. O., Reilly, J. J., \& Tomkinson, G. R. (2016). Global matrix 2.0: report card grades on the physical activity of children and youth comparing 38 countries. Journal of physical activity and health, 13(s2), S343-S366.

Tudor-Locke, C., Craig, C. L., Aoyagi, Y., Bell, R. C., Croteau, K. A., De Bourdeaudhuij, I., ... \& Matsudo, S. M. (2011). How many steps/day are enough? For older adults and special populations. International Journal of Behavioral Nutrition and Physical Activity, 8(1), 80.

Weiss, M. R. (2000). Motivating kids in physical activity. President's Council on Physical Fitness and Sports Research Digest, Series 3(11), 1-10.

Welk, G. (2002). Physical activity assessments for health-related research. U.S.A.: Human Kinetics.

W.H.O.(World Health Organization) (2019). Global action plan on physical activity 2018-2030: more active people for a healthier world. World Health Organization.

Wickel, EE, Eisenmann, JC (2007). Contribution of youth sport to total daily physical activity among 6- to 12-yr-old boys. Medicine \& Science in Sports \& Exercise 39(9): 1493 - 1500.

Yoon, G. A. (2001). Relationship of Weight Status and Physical Activity of Adolescents in Busan City. The Korean journal of nutrition, 34(1), 39-47. 


\title{
시기에 따른 중학교 남녀 학생의 일일 신체활동 분석
}

\author{
장종훈 ${ }^{1}$, 이규일 ${ }^{2}$, 박재영 ${ }^{3}$ \\ 1경북대학교 대학원생 \\ 1경북대학교 부교수 \\ 3경일대학교 교수
}

〔목적〕 이 연구의 목적은 3차원 가속도계를 활용해 시기(방학 중; VD - vaction day, 체육수업 있는 날; SPE: school day with physical education, 체육수업 없는 날; SNPE: school day no physical education) 별 남녀 중학생의 일일 신체활동량을 측정해, 성별(gender)과 시기에 따른 청소년기 신체활동 특성을 분석하 는 것이다. 〔방법〕 연구 대상은 남녀 중학생 130 명(남학생 68명, 여학생 62명)이었고, 자료 수집은 ActiGraph에서 개발한 3차원 가속도계(GT3X 모델)을 활용하였다. 수집된 자료는 신체활동 분석 프로그램 (Actilife v6.11.9)에 의해 강도별 시간과 비중으로 변환시켜 통계프로그램(SPSS 25.0)에 입력하였다. 통 계 분석으로 일원분산분석과 독립표본 $\mathrm{t}$-검정을 실시하였고, 시기 분석의 사후 검증은 Tukey's HSD으로 활 용하였다. 통계적 유의수준은 .05로 삼았다. (결과) 연구결과 세 시기(VD, SNPE, SPE) 중 체육수업이 있 는 날(SPE)의 중고강도활동 시간을 제외하고, 모든 시기에서 좌식활동과 MVPA 시간은 여학생에게서, 저강 도활동과 총신체활동 시간은 남학생에게서 유의하게 높게 나타났다. 남학생의 경우 총신체활동시간이 $\mathrm{SPE}$, $\mathrm{SNPE}, \mathrm{VD}$ 순으로 높게 나타났으며, 여학생의 경우, 학기 중(SNPE와 $\mathrm{SPE}$ ) 신체활동시간이 방학 중 보다 유의하게 높게 나타났다. MVPA 시간의 경우 남학생은 SPE, SNPE, VD 순으로 높게 나타났으며, 여학생 역시 $\mathrm{SPE}, \mathrm{SNPE}, \mathrm{VD}$ 순으로 높게 나타났으나, $\mathrm{SPE}$ 와 $\mathrm{VD}$ 에서만 유의한 차이가 발생하였다. 좌식활동 시 간의 경우 남녀학생 모두 $\mathrm{VD}, \mathrm{SNPE}, \mathrm{SPE}$ 순으로 높게 나타났으나, 방학 중 좌식활동 시간이 학기 중에 비해 유의하게 높은 것으로 나타났다. (결론) 연구 결과를 종합할 때, 첫째, 신체활동 공간으로써 학교와 체육 수업이 남녀 중학생의 신체활동 특히 MVPA에 유의미한 역할을 하는 것으로 확인되었으며, 둘째, 체육수업의 신체활동 효과는 남학생에게서 보다 효과적인 것으로 파악되었다. 본 연구의 결과를 바탕으로 이후 다양한 학 년에 대한 연구와 신체활동에 영향을 미치는 다양한 요인을 복합적으로 탐색하는 연구가 진행될 필요가 있다.

주요어: 청소년, 일상생활 신체활동 수준, 중-고강도 신체활동, 체육수업, 3 차원 가속도계 